\title{
BRUNONIAN PSYCHIATRY
}

\author{
by
}

\section{ROY PORTER*}

Medical men have been cast in a singularly dim light in recent histories of the formative years of psychiatry. We are told, correctly, that the medical ancien régime in such traditional institutions for the mad as Bethlem - a regime of routine and standardized bleedings, purges and vomits-was hidebound, rigid, and ineffectual. In the 1750s, faced with an extraordinary attack from William Battie, Dr John Monro defended his late father's reliance, as physician at Bethlem, on venesection and emetics as the best he knew. Some sixty years later, John Monro's son Thomas was in his turn defending the identical therapies, admitting their relative worthlessness, but saying that he "knew no better". This did not convince the House of Commons Committee before which he was giving evidence. That investigating body heard witness after witness chorus William Battie's maxim that insanity responded better to management than to medicine. ${ }^{1}$ Indeed, its Report lavishly publicized and seemingly endorsed the experiment of the York Retreat, an institution founded and run by lay Quakers, not physicians. There, medicines had been tried and found wanting, and had been replaced essentially by moral therapy: kindness, example, influence, all bearing on the mind and heart.

If the lay-dominated strategy of moral therapy thus struck a blow against the doctors, the medical profession retaliated, so Scull and others have argued, by striving to capture for itself both moral therapy and the asylums in which it was practised. ${ }^{2}$ Medical pressure upon Parliament successfully secured for medically-qualified superintendents exclusive legal control of the new public asylums, and thus effectively turned psychiatry into a medical monopoly. In reality, however, historians continue, medicine per se had nothing positive to contribute to the cure of the insane. The medications increasingly deployed in the Victorian asylum - bromides, croton oil and the like-had little more to recommend them than the ancient aloes and assafoetida had; and they merely paved the way for later, no less psychiatrically inappropriate, and indeed cruel psycho-surgery. Many of today's historians have very mixed feelings about the enterprise of psychiatry per se. But they have been almost united in dismissing the historical antecedents of psychological medicine as, essentially, classic examples of medical imperialism, which served, wittingly or not, to mask the real nature and causes of mental disturbance. ${ }^{3}$

* Roy Porter, PhD, Wellcome Institute for the History of Medicine, 183 Euston Road, London NW1 2BP.

${ }^{1}$ Cf. Roy Porter, 'Mind forg'd manacles'. Madness in England from the Restoration to the Regency. London, Athlone Press, 1987, ch. 4 for these developments.

${ }^{2}$ See Andrew Scull, 'From madness to mental illness: medical men as moral entrepreneurs', Eur. J. Sociology, 1975, 16: 219-61; idem, 'Mad-doctors and magistrates: English psychiatry's struggle for professional autonomy in the nineteenth century', Eur. J. Sociology, 1976, 17: 279-305; and more generally idem, Museums of madness, London, Allen Lane, 1979.

${ }^{3}$ See Joan Busfield, Managing madness. Changing ideas and practice, London, Hutchinson, 1986. 
Things were not, of course, so simple. Above all, medicine itself was never homogeneous; and so, a fortiori, there never was such a thing as a united face of psychological medicine, or of the medicine of the mind. Doctors of course tended to share, at the deepest level, a common approach to insanity, a tendency to look to organic aetiologies, and a faith in drugs as instruments of therapy. But there the unity ceased. To general medicine, Brunonianism presented a Young Turks movement, combating the entrenched orthodoxies of the age, ${ }^{4}$ and so it should be no surprise then that in psychological medicine too, John Brown's followers set out to challenge both the standard theories expounded at Edinburgh and other schools and the standard therapies deployed by physicians at Bethlem, in such public asylums as that at Manchester, and in the private trade in lunacy.

Research in depth would be required to demonstrate just how many, and to what extent, doctors both theoretically and practically active in insanity were devotees of the Brunonian system. John Brown himself took no special interest in mental disorder, ${ }^{5}$ though he of course had no difficulty in fitting mania and melancholia respectively into his general scheme of sthenic and asthenic disease. In Philadelphia, that errant Brunonian, Benjamin Rush, followed Brown's emphasis upon the explanatory power of the notions of over- and under-excitation, and embraced a therapeutics which, like Brown's, set great store by the virtues of opium; but Rush's claims that the aetiology of insanity lay in the blood and the vascular system, and his conviction that heroic venesection was the panacea, were essentially unique to himself. ${ }^{6}$ A similarly partial Brunonianism can also be found in Thomas Beddoes, whose root-and-branch attack in the Hygeia ${ }^{7}$ upon the nosological enterprise of carving up insanity into a complex taxonomy of classes and species precisely followed Brown's denial of the ontological theory of disease, and his faith in its essential unity and simplicity.

More wholly and authentically Brunonian was Robert Jones's An enquiry into the nature, causes and termination of nervous fevers; together with observations tending to illustrate the method of restoring His Majesty to health and of preventing relapses of his

\footnotetext{
${ }^{4}$ For interpretation, see Guenter Risse, 'Scottish medicine on the Continent: John Brown's medical system in Germany, 1796-1806', Proceedings of the XXIII Congress of the History of Medicine, London, 2-9 September 1972, London, Wellcome Institute of the History of Medicine, 1974, 682-87; idem. 'The quest for certainty in medicine: John Brown's system of medicine in France', Bull. Hist. Med., 1971, 45: 1-12; idem, 'The Brownian system of medicine: its theoretical and practical implications', Clio Medica, $1970,5: 45-51$.

${ }^{5}$ For Brown's own writings and a biographical account see The works of Dr John Brown, M.D. To which is prefixed a biographical account of the author, by $W$. C. Brown, 3 vols., London, J. Johnson, 1804.

${ }^{6}$ E. T. Carlson, J. L. Wollock and Patricia S. Noel (editors), Benjamin Rush's Lectures on the Mind Philadelphia, American Philosophical Society, 1981; Benjamin Rush, Medical inquiries and observations upon the diseases of the mind, 1812, New York, Hafner Reprint, 1962. For discussions of Rush's psychiatry see E. T. Carlson and M. M. Simpson, 'Benjamin Rush on the importance of psychiatry', Am. J. Psychiatry, 1963, 119: 897-98; idem, 'The definition of mental illness: Benjamin Rush (1745-1813)', Am. J. Psychiatry, 1964, 121: 209-14; F. Wittels, 'The contribution of Benjamin Rush to psychiatry', Bull. Hist. Med., 1946, 20: 157-66; P. S. Noel and E. T. Carlson, 'The faculty psychology of Benjamin Rush', J. Hist. Behavioral Sci., 1973, 9: 369-77; M. J. Wasserman, 'Benjamin Rush on government and the harmony and derangement of the mind', J. Hist. Ideas, 1972, 33: 639-42.

7 Thomas Beddoes, Hygeia, 3 vols., Bristol, J. Mills, 1802-3. For Beddoes, see D. Stansfield, Thomas Beddoes, Dordrecht, D. Reidel, 1984.
} 


\section{Brunonian psychiatry}

disease, published in $1789,{ }^{8}$ unfortunately for Jones just before George III's recovery from his first bout of insanity. Probably with a view to rescuing the King from imputations of being out of his mind, Jones contended that the royal disease was not "insanity" at all, but a "nervous fever". They were difficult to distinguish, he admitted, but the court physicians' reports before the Parliamentary committee clearly pointed to nervous delirium. Because this fever was "asthenic", the King's current treatment-the lowering regime of blistering, purging, etc., employed above all by the Willises-was utterly mistaken. Instead George's "debilitated state of body" required tonic treatments to build him up and sustain him: "He should now indulge in animal food, and a proper quantity of wine. Music, provided it is not too loud, will be of great service." Mental and emotional stimulus would also be beneficial: above all, access to his family should form part of a general strategy aiming to "invigorate, by all possible means, the body, and to afford every consolation to the mind."

Jones had nothing but contempt for the royal doctors. Their diagnoses had been inept; worst still, their wanton use of the term "insanity" had needlessly spread pessimism, on account of its connotations of being both a hereditary condition and an incurable disease. But as a young provincial physician whose book appeared at the worst possible moment, he found no audience and seems to have made no further contribution to interpreting or indeed treating mental conditions. Indeed, he published no further books of any kind.

A more substantial figure altogether, as a champion of Brunonian psychiatry, is George Nesse Hill. Born in 1766, Hill, unlike Jones, was too young to have been a pupil of Brown in Edinburgh (he seems to have studied mainly under Dr Maddocks at the London Hospital). He passed his career as a surgeon in Chester, claiming to have had "in early life the superintendence of two houses for the reception of lunatics", though little is known about his life. His claims to fame rest entirely upon his weighty 450-page tome, An essay on the prevention and cure of insanity-his only book - which came out in 1814, after, he claimed, "thirty years' experience" in handling the mad. ${ }^{9}$

There is no indication that Hill's treatise had any major impact upon contemporary thought or practice. Indeed, he was conspicuous in not being one of those called upon to give evidence before the Commons Committee the next year; nor was his book referred to at its hearing. And unlike, say, the writings of Samuel Tuke, Joseph Mason Cox, or Thomas Mayo, there is no sign that any of his volume's recommendations for the reform of the public treatment of the mad was ever acted upon. Indeed, therein lies his interest. For as a Brunonian writing thirty-five years after Brown's death, Hill was utterly out of step with his times. And his position as an old-style medical radical, a prophet crying in the wilderness, far away from the

\footnotetext{
${ }^{8}$ See Robert Jones, An enquiry into the nature, causes and termination of nervous fevers; together with observations tending to illustrate the method of restoring His Majesty to health and preventing relapses of his disease, Salisbury, Robinson, 1789. For discussion see I. Macalpine and R. Hunter, George III and the mad business, London, Allen Lane, 1969, 99f.

${ }^{9}$ George Nesse Hill, An essay on the prevention and cure of insanity, with observations on the rules for the detection of pretenders to madness, London, Longmans et al., 1814.
} 
mainstream, enabled him to stand as a very fundamental critic of his age. His work above all shows that medical men were by no means united in an endeavour to monopolize the control of mad people for themselves within the emergent asylum system.

Hill was by no means uncritical of Brown. ${ }^{10} \mathrm{He}$ had read widely in the English and Continental literature of his times, and absorbed a great deal from Struve and Pinel, as well as from Cox, Erasmus Darwin, "the acute Beddoes"11 and others. But his basic understanding of the nature of insanity was impeccably Brunonian. Health was the state when the body's excitability - that "wonderful and inexplicable property"12 which was a defining feature of life itself-was receiving the right amount of energy from exciting powers both external and internal ("equable stimulation" was his phrase). ${ }^{13}$ Too much or too little excitement produced sickness, sthenic or asthenic disease respectively. That kind of sthenic condition characterized by derangement and disorientation of the mind, of conduct and speech-its symptoms were ravings, delusions, non-stop chatter, and the like-was mania. That kind of asthenic distemper accompanied by mental collapse-by the narrowing of consciousness to a repetitious absorption with idées fixes, by vacancy, fatuity, and stupor-was melancholia. Or, put another way, mania set in when the excessively stimulated constitution erupted not merely in such physical symptoms as fever, but in mental agitation; and melancholia resulted when too little stimulus, under-excitement, produced not only such physical signs as debility, but an under-stimulated mind, manifest in such signs as idiotism or taedium vitae, bordering on suicide.

For Hill, characterizing madness thus was important for many reasons. For one thing, it radically and dramatically demolished the whole taxonomic fantasy-world originally created by William Cullen, who was "less clear and decided upon the subject of insanity than on any other disease", 14 and enlarged upon by Cullen's followers, among them Erasmus Darwin and-one of Hill's particular bêtes noires-Thomas Arnold. All such classificatory schema were hopelessly abstract, dogmatic, a prioristic and idealist. "The almost endless shades of difference branched out into species by learned Nosologists and Metaphysicians", grumbled Hill, "have no one beneficial tendency, being only calculated to encumber science, disguise truth, render rugged and disheartening the paths of enquiry to young minds", and so forth. ${ }^{15}$ The differentiae of mental illness did not identify clusters of distinct diseases with distinct and constant symptoms and signs; or rather they did so only in the crazy systems of obsessive theorists. Madness was a state, rather than an ontological entity. Insanity was a manifestation which, Hill stressed, had to be understood "symptomatically": "insanity is always a symptomatic disease". ${ }^{16}$ It was, as it were, a barometric reading on a particular individual, depending on quite individual propensities, balances, and

\footnotetext{
${ }^{10}$ For example, he criticized Brown's views on the use of evacuants in the case of asthenic diseases. Ibid., p. 340.

${ }^{11}$ Ibid., p. ix.

12 Ibid., p. 20.

13 Ibid., p. ii.

14 Ibid., p. 211.

15 Ibid., p. 57.

16 Ibid., p. xi.
} 
responses. An action or habit-for example, consumption of heavy quantities of alcohol-precipitating manic insanity in one person would be quite conducive to the health of another (indeed, for such a toper, leaving off heavy drinking might itself trigger incurable torpor). Thus it was a nonsense to approach any understanding of insanity by proceeding as Arnold and Darwin had, by cooking up a natural history of diseases. Insanity was rather to be understood as "one species" only, as a process characterized by physiological actions and reactions, stimuli and responses. ${ }^{17}$

Indeed, in order to handle particular manifestations of madness, it was of cardinal importance to know the individual. Detailed case histories, conducted in depth, were essential. For insanity was not an absolute but a relative matter; it registered a discrepancy between the healthy requirement for excitation of a particular constitution, and the quantum of stimulus being received or generated. For that reason, it was vital to understand the precise concatenation of pre-existing circumstances finally issuing in mental disorder. Of vast importance was the individual's constitutional diathesis, or, in other words, his general predisposition and habit. How much food, exercise, work, mental activity was he capable of and accustomed to? Age, gender, size, habit, early diseases, education, strength, occupation, physique, physiognomy (in the literal sense, for Hill admired Lavater): all these factors and many more (Hill termed them "predisponent causes") ${ }^{18}$ together amounted to an individual's diathesis towards mental illness. This applied in both an overall sense (how likely was such a person to succumb?), and more particularly (how would certain triggers-a brain injury, a personal calamity-affect particular individuals?). Without a detailed predispositional history, the symptoms of mental illness could be drastically, and even fatally, misread. Someone deeply agitated might mistakenly be diagnosed as suffering from mania, be given such drastic depletive treatments as heroic blood-lettings as a consequence, and thus might well become fatuous and be rendered incapacitated for life. By contrast, the expert diagnostician, with a knowledge of the diathesis in such a case, might well recognize the basically asthenic constitution and so pinpoint the therapeutic need, not for sedation and depletion, but rather for measured, exact, precise stimulus, especially to reactivate the stomach and bowels.

Indeed Hill believed, very much in the spirit of Brown himself, that it was asthenic conditions (often misjudged by superficial practitioners as sthenic) which actually posed the worst problems. Put another way, Hill, like Brown, distrusted the ready and easy recourse to depletive medicines and measures, not least the blood-letting which all too often was mistaken as a panacea in cases of frenzy and agitation. For Hill, proper knowledge of predisposing factors and the proximate causes of insanity would produce diagnoses which, in the overwhelming majority of cases would indicate that appropriately gradated and diversified stimulus which would induce that strengthening of the system which the restoration of mental health demanded.

A pillar of Hill's system, then, was the need to treat individual cases individually. Disease-centred approaches must give way to person-focused ones. Such mass and

${ }^{17}$ Ibid., p. xiii.

18 Ibid., p. v. 


\section{Roy Porter}

routine treatments characteristic of the madhouse as the group annual Spring blood-let and vomit at Bethlem, defended by the Monros and by John Haslam, all of whom served as Hill's whipping boys, were quite criminal. ${ }^{19}$

Above all, close attention to individual diathesis would prove fruitful in prevention. Hill called his book an Essay on the prevention and cure of insanity, and the attention he paid to prevention is quite unusual in the contemporary insanity literature, with its standard emphasis on the handling of the mad once they had already been delivered to the asylum. For Hill, an ounce of prevention was worth far more than a pound of cure, and with his emphasis upon diathesis, upon organic habit, upon the need for regular stimulus as the sine qua non of health, he believed that it was possible to follow "precautions" 20 and regimens which set a straight course for mental health. Moreover, friends and relatives should be able to spot the tell-tale signs of insanity when they first appeared-bodily changes, alterations in the eye and countenance, shifts in manners and habits - and to intervene in time to forestall disaster. Those on the brink of mania could be soothed by changes of habitat, scene and occupation; those sliding into melancholy could be stimulated by travel, by new hobbies, by a richer diet, by enlarging their circle of friends, and so forth. ${ }^{21}$

No less important to Hill, another shaft of light shed by Brunonianism onto insanity, was the theory's fundamental organicist holism. Sthenic and asthenic disease, mania and melancholy alike, were attributes of the entire organic system, a single, unitary "human machine", in which the body, "together with the mind [formed] one homogeneous mass".22 They were not just sited in, or excited by, the nerves, the liver, the heart, the blood (at this point, Hill certainly parted company with Rush), the guts or the uterus (Hill in fact says quite remarkably little about special diseases of women). They were not even principally lesions of the brain. Above all, they were emphatically not sited in some immaterial principle, some disembodied consciousness, some free-floating cogito.

Although Hill had the greatest respect for the insights of the associationist philosophy of mental mechanisms developed by Locke and enlarged by Hartley, he deplored metaphysical accounts of mental illness as absurd mystifications. It was arbitrary to separate mind from body, and it baffled understanding. Moreover, experience itself showed that immaterialism was just a tissue of "metaphysical cobwebs". ${ }^{23}$ The derangement of the mind could always be shown, by the observant physician, to be accompanied by such visible organic changes as a different skin colour, squinting eyes, a racing pulse, tics, and even, Hill claimed, a quite unmistakable fetid smell absolutely unique to the insane. But these manifestations did more than "accompany": they caused as well. For Hill repeatedly argued that such bodily defects as liver complaints, irritation or inflammation of the bowels, intestinal worms and fever brought about the characteristic mental over-excitation of mania, such as the inability to concentrate on any one subject for more than a moment, or of melancholy,

\footnotetext{
19 Ibid., p. iii.

20 Ibid., p. 240; see also p. $236 \mathrm{f}$.

21 Ibid., p. 264.

22 Ibid., p. 17.

23 Ibid., p. 35.
} 


\section{Brunonian psychiatry}

such as anxiety, anguish, hypochondria. Because "organic functions precede mental operations", 24 because "mind itself is the product of bodily sensation", 25 because consciousness stemmed from organized existence, because thought arose from the excitation of the senses connected to the nerves, there could be no mental disease without physical diathesis, without organic disease. Hill was insistent on this point. Insanity, he argued, "is never a purely mental disease"; it "always has corporeal disease for its foundation". 26

Characteristically, Hill favoured therapies initially and fundamentally involving the cleansing and rectification of the body: the use of emetics, laxatives and so forth. His strategy however was not routinely to deplete, but to rid the body of obstructions and toxic material. For all body waste typically produced pain, irritation and liverishness. Hill's goal was to tone up the stomach and the bowels, and to restimulate healthy body action.

Hill anticipated stigmatization as an evangel for a "cold and comfortless system of materialism". ${ }^{27} \mathrm{He}$ was, after all, publishing before the end of the Napoleonic War, in the aftermath of the "alarm" against the revolutionary materialist ideologies of the French Revolution. He emphasized, however, how his doctrine deserved to be embraced by all who had at heart the understanding of insanity, and the health of lunatics. For by stressing the corporality of insanity on the one hand, he removed madness from the realms of mystery, and rendered it as intelligible as all other diseases. On the other, he rendered insanity as amenable to medical therapeutics as other comparable diseases such as fevers. This paved the way for the second original feature of Hill's system: its distinctive, and highly impressive, therapeutical thoroughness. One of the noteworthy features of so many writings on insanity, in the half century preceding Hill, is how little they say about the medical management of the mad. Authors like Samuel Tuke ventured little because they thought that little was to be said. Others, like Thomas Arnold, were more interested in nosology, taxonomy and diagnosis. Still others, like Thomas Bakewell, were sitting on family nostrums which they chose to conceal (Hill found this practice quite scandalous). William Perfect would be an instance of those who used such stock items as aloes, bark and paregoric essentially as a "liquid cosh", to render the patient tractable. All of this neglect and imprecision Hill denounced, attacking the "inattention the rational method of curing insanity has experienced". ${ }^{28}$ In his view, "too little reliance has been placed upon medical agents in the cure of insanity, and too few a number of them have been employed to obtain the end in view". ${ }^{29}$ By contrast, he devoted close on two hundred pages to the rationale and the practice of drug therapies, not omitting such details of "efficacious medicines" 30 as how best to make up such drugs as digitalis, and thus avoid the adulterations of the druggists.

\footnotetext{
24 Ibid., p. 50.

25 Ibid., p. 37.

26 Ibid., p. xiii.

27 Ibid., p. 52.

28 Ibid., p. iv.

29 Ibid., p. 208.

30 Ibid., p. ii.
} 


\section{Roy Porter}

Hill recognized the indispensability of sedatives in handling mania, which was, after all, the disease of over-excitation; and he devoted many pages to assessing the value of camphor for this purpose (he approved), and to showing that hyoscyamus was in this respect better for melancholics than opium, his lack of enthusiasm for which distinguished him from Brown. Even so, the thrust of his pharmacy was always towards stimulus rather than depletion. If irritation caused mania, and irritation was often caused by obstructions in the guts or the bowels, the proper course of medicines-gentle purgatives, measured emetics-would aim to stimulate the regular, lively action of the digestive parts, normalize excitation, and so restore concentration. The effects could be seen. Hill argued that maniacs were habitually costive. Their vomits brought up vast quantities of mucous phlegm; purges removed hard, indurated faecal material. Both observations proved the essentially organic determination of the diseases of the mind.

To a large degree, therefore, treating the mad was a matter of the expert management of medication, requiring "practical observers" and "medical artists" rather than "speculative philosophers". ${ }^{31}$ Daily vigilance and flexibility were crucial, individual adjustment essential. Thus with purging, he noted, "whatever laxative is adopted, it must simply act as such day by day, being augmented, diminished, or wholly suspended, conformable to the strength of the patient and his peculiar habits and present circumstances". ${ }^{32}$ Hill believed therapeutics to be an art peculiarly neglected, partly because the physician all too often saw himself as superior to his drugs: once he prescribed, he felt his task complete. By contrast, Hill argued, the true physician would also make up, administer, and test the effects of his own medicines.

Particularly evil was the indiscriminate use, very common in large asylums, of pacifying medicines, largely as a way of ensuring tractability. Heavy sedation, low diet, cold and inactivity would combine to produce drastic under-excitement and enervation, which would convert a sthenic into an asthenic condition. Mania would turn to stupor, imbecility, and "fixed contemplation", leading to people permanently "encased in torpor". Such melancholy would prove radically incurable. ${ }^{33}$ Controlled and supervised medication with the right stimulants would prove a far superior technique for tackling maniacal conditions which, despite first appearances, were far more promising in their prognosis than were stupor and low spirits, simply because of the maniacs' high degree of excitability.

Herein were the existing lunatic asylums appallingly deficient. Either they neglected proper medication by design, preferring the metaphysical dogmatism of moral therapy; or they performed mass medication, rather as a missionary might perform mass baptism. Nothing was worse than the "routine of hospital practice, painful coercion, starving . . . bleeding ad libitum"-precisely what he found Thomas Monro and John Haslam defending at Bethlem. ${ }^{34}$ This was only one of a whole string of complaints Hill levelled against madhouses. Indeed, he comprehensively assailed them; they were, as he quoted from John Reid, "manufactories of madness", whose

31 Ibid., pp. 230, 250.

32 Ibid., p. 342.

33 Ibid., pp. 186, 234.

34 Ibid., p. 225. 


\section{Brunonian psychiatry}

existence largely pandered to the convenience of relatives and friends, but which were never conducive to the good of the sufferer. Radical hostility amongst medical men to the very institution of the asylum was not unknown: Andrew Harper-interestingly another surgeon-had made a comparable attack some thirty years earlier. ${ }^{35}$ But no contemporary questioned the rationale and the efficacy of the asylum per se, good or bad, so comprehensively or indeed so perceptively as Hill. Since his assault upon the asylum flowed quite directly from his Brunonian principles, it is important to examine it here.

Asylums had many individual faults, and all too many of them were run by "ignorant and barbarous keepers" ${ }^{36}$ But the very principle of the asylum was vitiated by three fundamental flaws. First, they necessarily gave general treatment-sometimes cruel, like beatings, sometimes ineffectual, like moral therapy-whereas mad people needed utterly personal treatment. Individual diet, individual medication, individually regulated doses of light, exercise, freedom, and so forth were essential for recovery. But madhouses necessarily standardized all these items, for large facilities lacked flexibility. Overall, the effect was disastrous. "It is often more difficult to repair the mischief induced by the improper treatment of madness than it would have been to cure the original disease". 37

Second, nothing could jeopardize chances of recovery more certainly than the herding of large numbers of the mad together. For one thing, Hill strongly suspected that madness was contagious, thanks to the odour or effluvia ("inbred air") ${ }^{38}$ which the insane emitted. For another, the mad were in constant need of the right kind of stimulus, which would enliven their spirits and concentrate their attention. How could the company of dozens of the low-spirited, torpid, and incoherent help the individual? No sooner would he begin to regain his senses, than he would find himself overwhelmed again by the inanity and fatuity of those around him. As lucid intervals supervened, it was absolutely essential that the environment of the mad person should be tailored towards normality. In the asylum, the convalescent mad person, finding himself surrounded by lunatics, was likely to relapse into chronic insanity.

Third, the asylum perpetuated in bricks and mortar what the metaphysical theory of insanity engendered in the mind. This was the notion that insanity was a special, unique, distinct disorder, a disease, which inevitably and rightfully carried shame, odium, and stigma: in short, the notion that insanity was "tainted". 39 Not least, as a consequence, insanity was believed to be hereditary. This was erroneous, Hill argued; but the belief which denied "every cheering ray" rendered it peculiarly difficult for families to handle. ${ }^{40}$ Because madness-unlike, say, intermittent fever-was shameful, parents or friends would not act upon it until it was confirmed and advanced; in other words, until it was too late, for what the lunatic needed above all was "early institution of the effective means of cure". 41 Then they would opt for the asylum on the principle

\footnotetext{
35 Andrew Harper, $A$ treatise on the real cause and cure of insanity, London, Stalker and Waltes, 1789.

${ }^{36}$ Hill, op. cit., note 9 above, p. iv.

37 Ibid., p. 176.

38 Ibid., p. 362.

39 Ibid., p. vii.

40 Ibid., p. xii.

41 Ibid., p. 174.
} 
of "out of sight, out of mind"; or, perhaps, because of the stigma would reclaim a loved one from care at too early a stage. Most appallingly of all, residence in an asylum would impress upon the consciousness of the sick person himself, at least as he recovered, the recognition that he was actually "mad". Dreadful, dishonourable and degrading, asylum confinement would create in the lunatic's mind "more terror than prison". 42 And the shock and stigma entailed would almost certainly trigger a relapse quite fatal to all hopes of lasting recovery.

In the name of humanity, and for the sake of therapeutic success, sequestration must be avoided. Brunonianism spelt out the alternative. There was nothing special about insanity: it was a condition, like all other diseases, of organic excess or deficiency. The hallucinations, the warped ideas, of the mad constituted no special problem, for such thoughts and passions were "secondary", merely symptomatic. ${ }^{43}$ Madness was as "generally curable as those violent diseases most successfully treated by medicine". 44 No special institution, no unique mad doctor, was needed. Indeed, quite the reverse:

The result of long attention to this matter enables me to state from the fullest conviction, and without the smallest hesitation, that not one recent case of madness however violent ought under any pretence whatever to be consigned to a public or private receiving house. ${ }^{45}$

What was required, as an alternative, was an expert regime of medication and controlled access to stimulus. The ideal doctor should have a "Lavaterian eye", should be a "vigilant observer", and should possess great "versatility". 46 This role was best conducted by a local physician, even by the family doctor; certainly by someone knowledgeable about the patient's general health and habits. Such treatment should not take place within the home, for all too often it had provided the root-cause of insanity in the first place. The ideal solution would be to board an individual lunatic either with, or under the supervision of, a regular practitioner interested in the care of the mad. Thereby all associations counter-productive of early treatment would be avoided, and the intensification of personal care would dramatically improve cure rates. Madhouses were, of course, cheaper than boarding with practitioners. But this economy was entirely false because all too often, madhouses merely confirmed madness and thus rendered the patient a lifelong charge on family or parish. True economy lay in curing the maximum number possible, and that required early intervention: "direct medical remedies can never be too early introduced, or too energetically applied". 47 Caught early, "nine out of twelve, or even ten, cases of madness admit of permanent cure". ${ }^{48}$ The only valid function of a madhouse was to house incurables.

The stages through which Hill arrived at these conclusions are not quite clear, although they flow logically and consistently from his Brunonian attachments. These commitments may well, of course, have reflected a certain self-interest. Hill's case

42 Ibid., p. 381.

43 Ibid., p. 258.

44 Ibid., p. xiii.

45 Ibid., p. 220.

46 Ibid., pp. 261, 361, 370.

47 Ibid., p. 205.

48 Ibid., p. 214. 
studies, appended to the end of his volume, show that he had applied the system he advocated; he claimed to have had the superintendence of two madhouses, experience which clearly disabused him of that expedient.

What is clear, however, is that he ended up penning the most dramatic rejection of the whole emergent system of care and treatment of lunatics, and the most closely argued alternative. In spite of Hill's arguments, asylums were reformed, fortified, enlarged, rationalized, liberalized, and reformed again and again. But Hill's prediction about their necessary failure proved substantially true. Only nowadays, perhaps, are we once more seriously grappling with the possibility that the distinction of psychiatry from general medicine may have proved a vast strategic mistake. 